Discussion Paper No. 13-117

\title{
Strategic Timing of Entry: Evidence from Video Games
}

Benjamin Engelstätter and Michael R. Ward

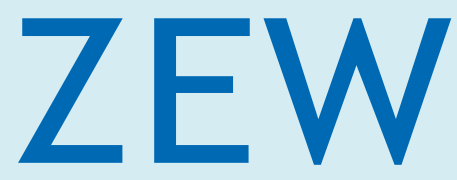

Zentrum für Europäische Wirtschaftsforschung $\mathrm{GmbH}$

Centre for European

Economic Research 
Discussion Paper No. 13-117

\title{
Strategic Timing of Entry: Evidence from Video Games
}

\author{
Benjamin Engelstätter and Michael R. Ward
}

Download this ZEW Discussion Paper from our ftp server:

http://ftp.zew.de/pub/zew-docs/dp/dp13117.pdf

Die Discussion Papers dienen einer möglichst schnellen Verbreitung von neueren Forschungsarbeiten des ZEW. Die Beiträge liegen in alleiniger Verantwortung der Autoren und stellen nicht notwendigerweise die Meinung des ZEW dar.

Discussion Papers are intended to make results of ZEW research promptly available to other economists in order to encourage discussion and suggestions for revisions. The authors are solely responsible for the contents which do not necessarily represent the opinion of the ZEW. 
“Strategic Timing of Entry: Evidence from Video Games”

\author{
Benjamin Engelstätter \\ Zentrum für Europäische Wirtschaftsforschung \\ Michael R. Ward \\ University of Texas at Arlington and \\ Zentrum für Europäische Wirtschaftsforschung
}

December 2013

\begin{abstract}
This paper investigates how video game publishers' choice of game release date is affected by the expected level of competition within the game's product niche. We identify game niches by genre, age-appropriateness, a four week window cohort, publisher and console system. Our analysis is based on two different video game data sets, one based on industry sales data and the other featuring extensive consumer usage information. We show that consumer substitution across games is stronger within most of the dimensions describing product niches. Sales volumes decay quickly after the opening weekend, so at any point in time, a niche will typically be served by few current titles. Thus, publishers have incentives to avoid releasing during periods of fierce intra-niche competition. We show that games are more likely to be released so as to avoid weeks when their niche is relatively well served.
\end{abstract}

Keywords: Product Entry, Non-Price Competition, Niche, Strategy, Submarkets, Entertainment Goods, Video Games

JEL Code: D43, L13, L96 


\section{Introduction}

Markets for entertainment goods, e,g, music, movies, books and video games, are often characterized by a continuous flow of new product introductions exhibiting considerable product differentiation and large differences in realized demand. Sales are largest upon release and fall steadily so that individual products tend to have short product lifecycles. A common outcome in these contexts is a relative de-emphasis on price competition with more attention to matching new product offerings to the heterogeneous tastes of the audience. As the new product launch date nears, a firm facing fiercer than expected competition can also adjust the product launch date. If product lifecycles are short enough, a delay in the launch date until the competitive environment improves may be more attractive than reducing price. We study this form of non-price competition based on product launch coordination in the video game industry.

Sales of video games in the US have doubled in the past decade to over \$10 billion annually, comparable to first-run movie ticket sales. Overall, video games feature many characteristics in common with other forms of entertainment such as movies and music. Games are characterized by a large degree of product variety in game content along multiple dimensions. For example, horizontal differentiation occurs across game genre, gaming platform, and the age appropriateness of content. Vertical differentiation occurs as some games are generally perceived to be better than others in terms of quality of gameplay, realism of graphics and the appeal of the story narrative. Video games face a very short life cycle and a rapid decay in sales after the first few weeks after release. Moreover, games depreciate quickly as a gamer will often complete a game within a few weeks. ${ }^{1}$ Demand for game play drops off

\footnotetext{
${ }^{1}$ Recently, games with extensive online multiplayer components may not depreciate as quickly. However, our data stems from 2004 to 2009, a time period where, e.g., the well known multiplayer game World of Warcraft just started and social features or downloadable content keeping gamers' interest for longer just beginning to be introduced.
} 
considerably after completing a game. Accordingly, publishers develop and introduce new games frequently in order to stay in the market. Furthermore, gaming often entails a degree of a social bandwagon effect in which peers prefer to play and discuss the same games simultaneously. This can result in some games becoming "blockbusters” seemingly out of proportion to the reported measures of game quality.

A useful analog for the market for video games is the market for movies (Calantone et al. 2010). There is a steady, though seasonal, flow of new product introductions. Sales for an individual product are strongest immediately after launch but fall quickly. While larger sales typically accompany greater investment in quality, there is still considerable uncertainty about an individual product's profitability even as it is launched.

The production of video games shares other features with other entertainment goods. As with many information goods, they generally exhibit large fixed cost of production and small marginal cost of duplication. Publishers can invest more in game production so as to develop a game of higher quality in order to increase game demand, however, there remains some uncertainty about the eventual perceived quality during the game development stage. Because many games place different storylines and action points on top of common computer code shared by multiple games, game production can exhibit substantial economies of scope. Developers may also have core competencies (e.g., computer code, graphic images, and story editors) that are relevant to narrow niches, i.e. specific submarkets, of games (e.g., console operating system, age group of audience, and style of play). Finally, advances in the underlying computer technology require developers to redesign even core game components from time to time.

Game publishers face a series of strategic decisions at certain junctures. A publisher must decide what intellectual property and core competencies to acquire. This could entail, for 
example, outsourcing a physics engine that governs the movement of virtual objects within the games to an independent developer or developing it in-house. The publisher must then decide how to exploit these core competencies by choosing which specific product attributes to incorporate into a game. This decision is usually associated with choosing a specific horizontal niche. Similarly, the publisher must decide where in the quality dimension it wishes to place its game. While there is some uncertainty about how a game will ultimately be received, market participants know that gamers value higher quality content along a number of related dimensions (e.g., graphics, storyline, response time, degree of difficulty, game "balance”, etc.) that require greater ex ante investment. Publishers decide whether to vertically integrate into game development versus outsourcing it to third-party developers (Gil and Warzynski, 2010). Most games are developed by the firm that will eventually publish it. However, the industry has seen some degree of vertical disintegration as developers have specialized in specific competencies. Once game development is nearer to completion, publishers decide on the extent of the marketing campaign to support the game. Until now, publishers have had some degree of flexibility to alter the release date but now must lock in a release date to correspond with the marketing campaign. A publisher may use current and expected market conditions to choose to delay the release of a game so as to avoid release dates when the competition within the game's niche is particularly fierce. Finally, publishers choose the price for the game. Much like movies and music, there is much less variation in new game prices than in new game unit sales.

We focus on the game release date decision and how it is affected by expected competition. Since this decision crucially depends on the importance of specific niches in the video game market, we identify niches and estimate the degree to which consumers substitute across and within niches. These analyses imply that releasing a game in a week when other within-niche games are particularly popular can greatly reduce the game’s overall sales. As game sales decline quickly with time on the market, delaying the game release date by just a 
few weeks could greatly increase sales and profits if competitors' games are already depreciated in gamers' attention.

Our analysis is based on recent video game sales data consisting mostly of top-selling titles from established publishers. The data illustrate that video game publishers are highly specialized in each of several different dimensions of product differentiation. For game demand we show that consumer substitution across games is stronger within each of these dimensions describing niches. Finally, we show that release dates appear to be adjusted so that games are released so as to avoid weeks when its niche is relatively well served.

This paper adds in various ways to the existing literature of new product entry and nonprice competition in markets with short product life cycles. First, we document the importance of niches for non-price competition with the incorporation of additional product characteristics, such as age appropriateness, genre and console into our model. Second, our use of weekly, rather than monthly, sales data better matches the release date strategic decision as video games are usually released for the peak weekend demand. Third, by incorporating both supply and demand features, we can offer a fuller explanation of various aspects of strategic behavior for non-price competition and product introduction timing.

\section{Previous Literature}

\section{a. Non-price competition}

Most entertainment goods share a common outcome of much less price variation than would seem to be warranted by differences in demand across products. New hit songs from top artists can often be downloaded at the same price as niche songs from newcomers. First-run movie prices for a blockbuster movie with ticket sales two orders of magnitude greater than a small arts film will be within $50 \%$ of the arts film. While video games allow for some more complex 
revenue models, this same pattern holds for them as well. ${ }^{2}$ Orbach and Einav (2007) explore the causes for these uniform prices in the case of movies. Given this uniform pricing, we focus on other possible strategic decisions. The key strategic decisions for firms appear to revolve around affecting the bundle of product features rather than price.

Accounting for firms' non-price activities to increase demand goes back to at least Chamberlain (1962). A long line of theoretical literature explores how firms choose multiple qualities (Mussa and Rosen 1978) or varieties of a good (Dixit and Stiglitz 1977, Spence 1976) to differentiate themselves from one another. Gandhi et al. (2008) analyze the incentives of firms after consummate a horizontal merger to respond to the change in competition by repositioning their products, as opposed to the usual price adjustments. Industries for which non-price competition has been studied include dry cleaners (Plott 1965), airlines (Douglas and Miller 1974), hospitals (Joskow 1980) and food retail (Richards and Hamilton 2006). Instead of, or in addition to, price this literature highlights the roles of regulation, product quality and variety as drivers of demand.

For entertainment goods, a well-established prominent driver of sales instead of price is the perceived quality of each product (Calantone et al. 2010). Sales have been found to be related to quality measures derived from expert reviews or consumer ratings for books (Chevalier and Mayzlin 2006) or movies (Reinstein and Snyder 2005, Palsson et al. 2013). Bounie et al. (2005) and Zhu and Zhang (2010) show that consumer reviews positively influence video game purchasing decisions. Such ratings and reviews are valuable pieces of information as books, movies, and video games are complex experience goods for which consumers cannot know their preferences without consuming. Other suspected drivers of

\footnotetext{
${ }^{2}$ Full price titles from established publishers, often referred to as AAA, are usually priced within the same narrow band. An exception is the recent phenomenon of free-to-play games which are often supported by advertising or within game purchases. For console games the pricing scheme is even more rigorous as consoles predominately feature AAA, full-price titles which are priced similarly across publishers.
} 
demand and supply in the video game industry besides perceived quality or pricing are indirect network effects (Clements and Ohashi, 2005), installed base Chao and Derdenger, 2013), backward compatibility (Claussen et al. 2010) or cannibalization (Grohsjean and Kretschmer 2008).

\section{b. New Product Entry}

Successful new product introduction has been found to be related to strategic interactions between incumbents, the nature of the development process and aspects of the market environment such as market potential (Henard and Szymanski 2001; Montoya-Weiss and Calantone 1994). In addition Calantone et al. (2010) or Robinson and Fornell (1985), among others, also expect the entry timing decision and order of entry to impact new product performance. This research sheds light on the risks of pioneering compared to missed opportunities of delaying and presents possible strategies on how to improve new product performance in both cases (e.g. Rodríguez-Pinto et al. 2011; Vakratsas et al. 2003; Kalyanaram and Urban 1992). Early entry may result in access to advantageous market and resources (Robinson and Fornell 1985). Late entry, however, can help firms to leapfrog earlier entrants with regard to their technological product characteristics (Bayus et al. 1997; Lieberman and Montgomery 1998). Cannibalization of firms’ existing products on the market can also drive the decision for new product entry (van Heerde et al. 2010; Moorthy and Png 1992) as firms are reluctant to cannibalize their existing success (Grohsjean and Kretschmer 2008) or may use cannibalization as a protection mechanism to maintain market leadership (Nault and Vandenbosch 1996). The competitive environment in the product's target market at its launch will impact the release date. Currently available products from incumbents and products from competitors entering at the same time could substantially reduce new product performance (Calantone et al. 2010). With the exception of Calantone et al. (2010), little research has been 
conducted to explore entry timing decisions of firms trying to avoid such head-to-head competition (Krider and Weinberg 1998). Using the movie industry as empirical setting, Calantone et al. (2010) show that the performance of a focal product decreases if similar incumbent products are available or other new related products enter at the same time. In general, the negative impact is bigger for incumbent products than for other new entrants. We extend the analysis of Calantone et al. (2010) as we not only confirm their results, showing that incumbents' products indeed decrease new product performance, but also illustrate that producers are aware of this competition and try to adjust their product launch timing strategically to avoid it. Our analysis is based on the video game industry for which we explore several different submarkets (Urban et al. 1984), so-called niches, as strategies are often formulated based on the product's relative categories since these are expected to be the primary source of competition (Calantone et al. 2010).

\section{Methods}

We employ two separate methodologies that help identify the competitors of a newly released video game. First, we develop a model of video game demand based on the product characteristics of the game. These include both horizontal product characteristics - console, genre, age appropriateness, and cohort - and vertical product differentiation based on game quality. As with many entertainment goods, prices at the time of release do not vary across games in proportion to demand, if at all. However, as with many entertainment goods, demand for an individual game is largely determined by the perceived quality of the game. Thus, our model relates the demand for a game both to its own quality as well as the quality of current games in the same niche based on observable characteristics. 
Second, game publishers have an incentive to avoid releasing games concurrent with close competitors. As with many entertainment goods, demand is highest during a game's opening week and falls steadily and quickly afterwards. If a strong concurrent competitor will decrease opening week demand, the publisher may seek a different release date with fewer competitors. We test this by comparing the pattern of releases across weeks for various definitions of niches.

\section{A. Video Game Demand}

To identify the importance of niches, we estimate the demand for video games, with special attention on measures of product differentiation and the attributes of currently popular games. As discussed above, there is little price variation across video games; at most it accounts for a small fraction of the variation in demand. Instead, we exploit how game quality affects game sales. There is evidence that games of higher perceived quality sell many more units, all else equal (Zhu and Zhang, 2010). We exploit the variation in game quality of both the focal video game and games likely to be its competitors to identify which characteristics lead to substitution across games.

We relate sales of a game title over time to time on the market, its own quality and the quality of currently available games with similar horizontal features. Niche related substitution patterns are examined by adding quality measures averaged over the various dimension describing the niche the game occupies. To begin with, we include the average quality of all other games currently sold. We add additional variables to measure the number and average quality of the other games for the same console, in the same genre, granted the same ESRB rating, in the same cohort and from the same publisher. This results in the following specification: 


$$
\begin{aligned}
& \ln \left(\text { Quantity }_{i t}\right)=\alpha_{1} \text { Qual }_{i}+\alpha_{2} \text { Age }_{i t}+\gamma X_{i t}+\beta_{\text {oth }} Q_{\text {ual }}^{\text {Oth }} \\
& +\sum_{n} \beta_{\text {Oth, },} Q u a l_{i t}^{\text {oth }, n}+\varepsilon_{i t} \text {, }
\end{aligned}
$$

where Qual and Age refer to the focal game and Qual ${ }^{\text {Oth }}$ refers to average quality all other current games. The vector $X$ includes various control variables for the year, the week of the year, and the day of the week. It also includes dummy variables for the niche the game occupies. We hypothesize that $\alpha_{1}$ is positive and $\alpha_{2}$ is negative, as indicated in figure 1 . Indeed, figure 1 suggests that $\alpha_{2}$ is large in absolute value.

The additional terms measure competition across games. First, when all other currently released games are of higher quality, sales for any one game are smaller. Thus, we hypothesize that other current games are substitutes for the current game so that $\beta_{\text {oth }}$ is negative. In addition, $N$ indexes the different possible niches: console, genre, ESRB, cohort, and publisher. We hypothesize that other current games in the same niche, as defined by these product characteristics, are more similar to the game in question and will be closer substitutes. Some dimensions of similarity - like console, genre, and ESRB rating - are standardized descriptors for video games. Beyond these, we suspect that consumers tend to group together games that are released near each other in time. We define four week cohort windows to test for increased substitution among these games. Consumers may view their choice set to mainly include games that were released concurrently. Finally, games from the same publisher may share common characteristics that are not observable to the researcher. The artists who create the music or imagery may be the same, they may share the same design philosophy, or they may be part of the same character "universe.” To test for these consumer substitution patterns, we construct the average quality of games belonging to the same group along each of these five dimensions of niches. This implies that the coefficients $\beta_{\text {Oth,n }}$ would also be negative. 
Our set of control variables, $X$, includes an extensive set of dummy variables. First, we have sets of dummy variables for each niche dimension: the various consoles, genres, ESRB ratings, four-week cohort groupings, and the most popular publishers. We model seasonality with 52 dummy variables for the weeks of the year of the observation. Video game demand is highly seasonal with peak purchasing for the Christmas holiday and peak playing when school is out. Finally, we include year dummies as there is a secular increase in video game demand over the sample periods.

The distribution of games across niches and quality level is not likely to be random across observations. In fact, we provide evidence below consistent with publishers attempting to release games so as to avoid periods with the fiercest competition. Supply side decisions such as focusing on non-saturated niches will affect the market composition and may therefore lead to biased estimates of our measures of the sources of competition. Unfortunately, we do not have an identification strategy to address the possibility that the characteristics of other current games may be endogenous to the focal game's introduction. However, two aspects of this market allow us to possibly sign the bias. First, the magnitudes of consumer demand parameters are likely to dominate the effects from a non-random composition of competing games. Second, we expect that the bias is toward zero implying that our estimates would be lower bounds (in absolute terms) for the true parameter (Klepper \& Leamer, 1984). This is because, if possible, publishers will tend to stagger the releases of close substitutes rather than bunch them together in order to avoid periods of fierce competition. This would lead the set of current games that the focal game is competing with to be less similar than if they had been selected at random. The similarity of products that would remain would be due to the inability to perfectly avoid currently saturated niches. This lack of similarity implies that the quality levels of the focal game and the other current games occupying its niche will be negatively correlated which will tend to bias parameter estimates downward. 


\section{B. Video Game Entry}

As mentioned above, we expect publishers to attempt to avoid releasing their games during periods of the fiercest competition. A game's peak popularity is almost always the week it is released with demand falling quickly over time. This implies that another game in the same niche is a greater competitive threat when it is newer than the same game when it is older. The substitution away from any individual game would be smaller when the most similar games are older. If these substitution effects are large enough, it could be profitable for a publisher to delay or expedite the release of game when it anticipates other releases for the planned launch week. Indeed, up to a point, it would likely be profitable for publishers to coordinate release dates, either explicitly or tacitly, so that potentially competing games’ releases are spread out over a year rather than bunched together. One implication of this is that the number of releases within a niche in a given week would be negatively correlated with the number of popular games in that niche in the previous week.

We test our hypothesis by relating the number of games released in a niche in a week to the degree of competition observed in that niche in the previous week. The measures of the degree of competition available are: the number of entrants, the number of game titles, and these games' sales in the previous week. We model the number of releases as a Poisson regression equation from a balanced panel of week by niche observations:

$$
\text { Entry }_{n, t}=\exp \left(\beta \text { Competition }_{n, t-1}+\gamma X_{n, t}+\varepsilon_{n, t}\right)
$$

As the number of releases is a count variable, equation (2) is estimated using the negative binomial regression estimator. Models for each niche are estimated separately by creating a balanced panel where each niche value and week represents an observation. For example, for 
age appropriateness, there are four observations in week $t$, one each for ESRB values of E, E10, T and M. Since there are six console categories and eight genre categories, the number of observations differs by niche.

Publishers coordinating on release dates would imply that fewer games will be released in a niche in weeks when the previous week saw more games released in that niche so that we test whether $\beta<0$. Our controls, $X$, are related to other factors that may shift the distribution of game releases in a week. Some niches are more popular than others necessitating dummy variables for each niche. Furthermore, there is evidence that some niches became more or less popular over the sample period, especially consoles. To account for this, we also include niche by year dummy variables. Finally, because game sales are highly seasonal, we include 52 week dummy variables.

\section{Data}

Two separate data sets are used to investigate the nature of competition among video games. First, we have constructed a sample based on over one thousand popular console-based video games released over a four year period from 2005 through early 2009 from VGChartz. ${ }^{3}$ Besides some game characteristics, these data include weekly sales of the top 50 selling, predominately AAA, console video games in the US. For each game, we have added information regarding its quality from Gamespot, ${ }^{4}$ a professional video game rating firm whose staff reviews each game in our sample, and its rating for age appropriateness from the Entertainment Software Rating Board (ESRB). ${ }^{5}$ The second data source comes from users’

\footnotetext{
${ }^{3}$ See http://www.vgchartz.com

${ }^{4}$ See http://www.gamespot.com

${ }^{5}$ See http://www.esrb.com
} 
playing activity within the Raptr ${ }^{6}$ online platform, a social network site similar to Facebook but intended and specialized for video gamers. These are very granular data that, among other information, include the gaming sessions played by nearly 200,000 users over a 22 month period. We describe all databases in more detail in the following.

\section{A. VGChartz Data}

VGChartz reports weekly unit sales for each of the top 50 selling video console games in the US on their website, providing a dataset consisting of 1,192 different titles from 2005 to early 2009. The data that were obtained are for games designed for nine different gaming consoles. However, the sample contains few games for the consoles Game Boy Advanced, GameCube and Xbox as these systems were being replaced by newer systems, so the 42 games for these consoles were dropped from the sample. The remaining six consoles in our analysis are Nintendo DS, PlayStation 2 and 3, PlayStation Portable, Wii and Xbox 360. Overall, the Xbox 360 and Playstation 2 are the most common consoles in our sample, accounting for about $24 \%$ and $20 \%$ of games surveyed, respectively.

VGChartz provides the developer and publisher for each game listed. Often these are the same firm but even some vertically integrated publishers also publish games developed by other firms. We focus on release decisions made by publishers. Considerable effort went into determining which studios were subsidiaries of a common publisher resulting in 42 distinct publishers. The sample includes some large publishers, such as EA who are responsible for more than 200 games in our sample, and smaller publishers such as Valcon or Zoo Games, each with one game in the sample.

\footnotetext{
${ }^{6}$ See http://raptr.com
} 
The game genre classifications that were obtained from VGChartz were too narrow for the type of analysis we intend. Instead, we group the genre information into broader categories based on the genre definitions from Gamespot ${ }^{7}$ as described in Egenfeldt-Nielsen et al. (2008). For example, since the sample contains few racing and adventure games, we included racing games in the sport category and group adventure games together with role playing games as they share similar content. In addition, we include a genre category for music and party games, e.g. Guitar Hero, which comprise about one tenth of all games. Nevertheless, classifying games in one specific genre is problematic as some games could easily be categorized into two different genres, such as Mass Effect which features both action as well as role playing aspects. Overall, about 52 percent of the games of our sample include some sort of action, followed by sports (28 percent) and role playing games (26 percent). As many games feature an action theme as a second genre classification we decided to take the other genre as their main genre when forming distinct genre classifications for our estimations.

The age appropriateness ratings for each game assigned by the ESRB board are E, E10, $\mathrm{T}, \mathrm{M}^{8}$ where E classifies games suitable for everybody, E10 for everyone aged 10 and up, T for teens and $\mathrm{M}$ games for a mature audience. ${ }^{9}$ The ESRB is an industry-supported, nongovernmental body with the goal of providing a simple system to inform parents about the content of the games their children may want to play. In this sense, it plays a similar role to the Motion Picture Association of America (MPAA) ratings for movies. We identified the ESRB ratings for each game in the sample. Overall, categories with the most games are those suitable for everybody (33\%) or for teen audiences (34\%).

\footnotetext{
${ }^{7}$ Overall, there is no standardized principle for defining video game genres making the selection somewhat arbitrary. However, Gamespot has developed a broad competence in assessing and valuing video games making its genre definition a suitable choice for our data.

${ }^{8}$ Technically there is also a rating of A for adult content only. However, this rating is rarely applied and covers mostly games with pornographic content. Our data do not contain games with this rating.

${ }^{9}$ A detailed description of the mechanism determining the assigning of the ratings can be found in Federal Trade Commission (2007) or at the ESRB website.
} 
Our measure of game quality derives from the expert review data from the GameSpot website. Launched in May 1996, GameSpot provides the latest news, reviews, previews and links to portals for all current platforms. It also includes a list of the most popular games and features a search engine for users to track down games of interest. Almost every game in our sample was reviewed by the GameSpot staff who assigns ratings on a scale from 1 to 10 . These so called GameSpot-Scores (GSS) are intended to provide an at-a-glance sense of the overall quality of the game. The overall rating we collected is based on evaluations of graphics, sound, gameplay, replay value and reviewer's tilt. The quality rating of the games can be expected to be positively correlated with their sales as better-rated games usually are more highly demanded (Zhu and Zhang, 2010). However, it is possible that this relationship differs for games based on a popular tie-in from a sequel or a movie, e. g., the Final Fantasy series or the Harry Potter franchise. If developers anticipate that these games will sell well due to their popular tie-in, they may anticipate lower the returns to investment in game quality. In our samples, tie-ins and sequels are rare. The same line of thought might also hold for common branding franchises where a game is following a predecessor by, e.g., being the current setting of an existing universe or the current season of a professional sport franchise. Our specification implicitly assumes that the effects of such branding that carry over to the current game are mostly captured by the various niche dummy variables and the measures of quality.

For each game title, we observe weekly unit sales information so long as the game remains in the top 50 sellers. Similar to first-run movies, the week is a natural unit of aggregation for the sale of games as they are typically released for more intensive weekend play. We observe more weeks of data for more popular games that remain among the top 50 sellers for longer. On average, we observe 10 weeks of sales data per game, but there is considerable variation. Figure 1 depicts the distribution of weeks in the top 50 for our data. Almost all video games in our sample exhibit a strong decline in sales after its release date. 
Figure 2 depicts this decline for the average game. Finally, there is considerable variation in the popularity of different game titles. Figure 3 depicts the distribution of the natural logarithm of unit sales for the initial week after the game's release.

\section{B. Raptr Data}

We obtained user data from the Raptr platform for the period from January 2010 to November 2011 for 195,337 distinct users. Raptr is the leading online social network community for gamers with up to 17 million users currently. It offers gamers several services that are available in-game, on the web, and on mobile devices. Each Raptr user's console or PC is linked to the Raptr client with the user receiving an individual profile in the social network that tracks all his gameplay activity for each individual game. Users can link to each other “friend” each other - to communicate within a common social circle. Raptr offers a condensed, personalized news feed aggregating interesting discussions, news, videos, screenshots, and strategy guides based on the games the user, or his linked social circle, are currently playing. The Raptr client provides useful in-game features to gamers such as cross-platform IM chat, web surfing, access to popular social media services as well as video and screenshot capturing that all facilitate the coordination of gameplay. In our overall data we observe 37 million gaming sessions by 195,337 distinct users.

Several different pieces of information are available for each gaming activity. Most importantly, for each session we observe the game title. Within the time period for which we have Raptr data, we examine the 363 games that had 500 or more user-specific gaming sessions. The games featured in RAPTR are either based on the PC (34.3\%) or Xbox (65.6\%) as the RAPTR client was only able to track these two platforms during this time period. More than 95 percent of these games are full price AAA titles making the RAPTR data highly comparable to the aforementioned VGChartz data. 
For each game and for each day, we can aggregate the total duration of time spent playing the game across all users. For each game, we obtained information on the game's release date, genre, ESRB rating, and gaming console. We used metacritic data for our measure of game quality. ${ }^{10}$ Metacritic aggregates reviews across multiple reviewers for entertainment goods such as movies, games, television, and music. Most popular games are reviewed by multiple but not always the same critics. Because critics can have idiosyncratic biases, our measure is the average score after netting out a critic’s individual fixed effect and normalizing by the critic's individual standard deviation in scores.

\section{Empirical Analysis and Results}

Our data allow us to generate measures of horizontal differentiation (console, genre, ESRB rating, cohort, publisher) and vertical differentiation (Gamespot or Metacritic score). These allow us to define niches and measure within and across niche substitutability. Furthermore, during any week (VGChartz) or day (RAPTR), we can use VGChartz sales data as well as number of adopters and accumulated play time reported by RAPTR to measure how well the industry and each publisher are serving each niche. We link this niche level sales information to a multi-dimensional state variable and conjecture that publishers respond to the current values of this state variable.

First, we estimate a video game demand function that provides evidence of greater substitution across games within similar product attributes defined along these dimensions. Having established that video game niches are important, we then estimate a hazard function for time between a publisher's game releases to show that publishers tend to alter the release date of games to avoid periods when the game's niche is already saturated with popular games.

\footnotetext{
${ }^{10}$ http://www.metacritic.com/
} 


\section{A. Consumer Substitution Across Games}

Table 3 reports the results of various specifications of our estimation of equation (1) using the VGChartz data. Each observation represents the weekly unit sales of a game so long as it remained among the top 50 sellers that week. Because the sample includes only top 50 games, the distribution of error terms is truncated so that values that would imply sales below the minimum value for a week are not possible. We therefore adopt a maximum likelihood estimator that truncates the error distribution at the minimum sales value for the week. As expected, the truncation parameter is estimated to be significantly different from zero in all our specifications indicating that a non-truncated normal distribution assumption would be inappropriate.

Video games exhibit strong seasonality, especially around the Christmas gift giving season. Accordingly, as outlined in section III, we account for seasonality in all specifications with 52 week-of-year dummies. Since the data span more than four years which were affected by macroeconomic shocks, we also include year dummies. Finally, since our substitution variables are interactions with the different dimensions describing a niche, we include sets of dummy variables for each of the niche dimensions: six for console, eight for genre, four for ESRB rating, eight for cohort, and eight for major publisher.

We begin with the most basic specification and then introduce regressors that better uncover niche substitution behavior. In column 1, the only time varying regressors are the game's GameSpot score and its age in weeks. With children's games being not as time sensitive we include separate age variables for games with an ESRB rating of "E” or "E+" versus those rated “T” or "M.” As expected, sales are higher for games deemed to be of higher quality and are lower in games’ age, especially for those not directed toward small children. 
Column 2 adds the average GameSpot score for all other games over that week's top 50 sellers. Consistent with competitive pressures, game sales are significantly lower when other concurrent games are of higher quality. These effects are large. An increase by one standard deviation in own and other GameSpot scores, 1.26 and 0.22 respectively, imply a 52\% increase and a $38 \%$ decrease in sales respectively.

Next we investigate whether within niche substitution is stronger compared to between niche substitution. Column 3 introduces the variables that average GameSpot scores only for games in the same niche as the dependent variable for each dimension of possible horizontal differentiation: console, genre, ESRB, cohort, and publisher. First, we find that the effect of all other games is no longer significantly different from zero. This suggests that not all other games are of equal substitutability. The games in the same niche exert more competitive pressure than the average game. Second, the estimates for the niche parameters are all negative but only those for console and cohort are significantly different from zero at the $5 \%$ level, while those for genre and ESRB rating are significant at the $10 \%$ level. Those from the same publisher have a negligible effect, possibly because the publisher has more discretion over the release date of potentially cannibalizing games. The magnitudes of these effects can be gauged by calculating the effect of a one standard deviation increase in each variable. These are as follows: console $-8.9 \%$, genre $-13.9 \%$, ESRB rating $-30.8 \%$, cohort $-16.6 \%$ and publisher $1.9 \%$. If a game was unlucky enough to have a one standard deviation higher quality level in all competing niche dimensions simultaneously, demand is estimated to be $72 \%$ lower. This would be a large effect on demand and would substantially decrease profitability.

We re-estimate equation (1) using the daily Raptr data. Since these data include all games played and not just the top 50, we use a standard OLS estimator. However, these data allow us to identify both purchase behavior with the number of gamers who first begin playing a game and consumption behavior with the number of hours played. For the games in this 
sample, our measure of quality is from the standardized Metacritic score as described above. As these data are daily, we add day-of-week dummies to the set of control variables. Also, because the usage data are affected by new users joining the Raptr network, we include dummies for each of the 94 weeks. As before, dummy variables are included for each of the values of the niche dimensions.

Table 4 reports estimation results. As with the VGChartz results, columns (1) and (4) indicate that game quality and age greatly affect video game purchases and consumption. Likewise, columns (2) and (5) introduce the average quality of all other currently played games and are estimated to be negative. Since the Metacritic and Gamespot scores are on different scales, the coefficients are not directly comparable to those in table (3). However, a one standard deviation in own and all other Metacritic scores are estimated to imply a change in adoptions of $41 \%$ and $-16 \%$ respectively, somewhat smaller effects than estimated with the VGChartz data.

Finally, columns (3) and (6) include quality variables for each of the niche variables as well as the quality variable for all other games. As before, the estimated coefficient on the quality of all other games is smaller in absolute terms when the niche variables are included in the specification. In fact, now they become positive and significant suggesting that games are complements with games in other niches. As before, the niche variables tend to be negative. The exceptions are the genre niche which is positive and significant but small in magnitude, and ESRB rating which is not significant for adoptions. A one standard deviation increase in the average quality along each niche dimension leads to a change in adoption of $-44.4 \%$ for consoles, $+1.9 \%$ for genres, $-0.7 \%$ for ESRB rating, $-8.2 \%$ for cohort and $-11.4 \%$ for publishers. A one standard deviation increase in all dimensions simultaneously would decrease sales by $-62.8 \%$ without including the effect from all other games and $-47.7 \%$ once this effect is netted out. 
The two datasets used in our empirical analysis offer qualitatively similar results. In both cases, a large amount of the variation in game sales is due to game quality. In both cases, game sales fall quickly, between 8.5 and 9.8\% per week, and game sales are substantially lower when the overall quality of the other currently available games is higher. Finally, in both cases, the quality of other games with similar product characteristics has an even larger effect on the focal game's sales. There are some differences in the estimated magnitudes of the effects for different niche dimensions. This could be because they represent different sets of games and users. However, it appears that the important dimensions are console, genre and cohort with less support for age appropriateness and a common publisher. Taken together, this evidence indicates that there is substantial substitutability across the games currently available to consumers. A publisher releasing a game during a period in which many high quality games are already available will face depressed sales. Moreover, if these other games share features in common with the newly released games, sales are decreased even further.

We can use these estimates to get some idea of the value of avoiding such weeks in which many high quality games already compete. Let us suppose that, in the week of a planned game release, the average Gamespot score for other games is one standard deviation, 0.22, higher than average. If a publisher could delay the release one week, how much would the VGChartz estimates imply that this game's sales would increase? Over time, the higher quality, currently available games will be replaced with games of average quality implying that the quality of competing games regresses towards the mean level of quality. On average, 4.52 new games enter and exit the top 50 every week. If the new games were drawn from the set of all games and replaced games drawn from the current top 50 games, then their average Gamespot score would be expected to fall in subsequent weeks by $0.020,0.039,0.055$, etc. as more of the high quality games are replaced by typical games. 
Based on the coefficient estimate of -1.720 from column 2 of table 3 the expected decrease in Gamespot score of all other games leads to increased sales of 3.5\%, 6.7\%, 9.5\%, etc. in subsequent weeks, reaching out to $25 \%$ higher ten weeks later. While typical games replacing better games would occur regardless of a publisher's entry decision, delaying the game release one week would imply that these relative increases in sales would occur sooner within the product's lifecycle. By delaying one week, sales could increase by about $9 \%$ on average over the first ten weeks after release. A similar calculation assuming the quality in each niche dimension was one standard deviation above the mean implies about a $17 \%$ increase in sales over the first ten weeks from delaying game release by one week.

The above calculation suggests a substantial increase in profits from delaying entry by just one week in these circumstances. These could be overestimates because fewer of these highly rated games are likely to drop from the top 50 in any week, because a delayed game may not sell as well, and because there could be some additional marketing expenses associated with the delay. Nevertheless, these additional factors are likely more than offset by a $17 \%$ increase in sales over the game’s first 10 weeks. Indeed, this makes clear how delaying the game’s release could be a more important strategic decision than, say, reducing price.

\section{B. Entry Decisions to Avoid Saturated Niches}

The above analysis demonstrates the importance of substitutability across games. It also suggests that substitution may be larger within product niches and indicates which of the niche dimensions generate more substitutability than others. Any specific firm will have a comparative advantage in a subset of possible product characteristics. Consumers typically substitute mainly within a subset of product characteristics. Moreover, since the sales of the typical game decay quickly, around 8\% per week, the viable lifecycle of a typical game, once 
launched, is short. The above analysis also indicates a potentially substantial return to timing a game's release so as to avoid periods in which a game's niche is already saturated. Here we report results of our test of game release date timing to avoid competition.

We hypothesize that in the weeks, and perhaps months, prior to game release, publishers become aware of the expected release dates of competitors. Given the rapid expected decay in sales, they attempt to adjust their game release date so as to avoid periods with the fiercest competition. As a proposed launch date nears, the information about the quality of these expected releases becomes more firm. At this time, it may become even more imperative to adjust the product launch.

The results of the entry regressions based on equation (2) from the VGChartz data are reported in table 5. The first panel, for console niches, reports different specifications of a Poisson regression of the number of entrants in a console type in a week as a function of the degree of competition in the previous week. All specifications include dummy variables as controls for year, week-of-year, console as well as console by year interactions as outlined in section III. ${ }^{11}$ The three measures of competition in the previous week are: the number of games launched in the previous week for the same console, the number of titles within the top 50 games for the same console, and the unit sales of games for the same console in the previous week. In all cases, the coefficient estimate on our competition measure is negative as hypothesized, but it is only significantly different from zero for unit sales. The other two panels repeat the analysis for genre and ESRB rating. Again, all coefficients of interest take on the hypothesized negative value and six out of nine are significantly different from zero. Note that the strongest results here are for the Genre and ESRB product quality dimensions. These are the characteristics with the largest coefficient magnitudes in sales demand estimates from table 3.

\footnotetext{
${ }^{11}$ This last set of dummies is meant to control for the changing popularity of consoles over the time period.
} 
For completeness, we repeat the analysis using the Raptr data. In this case, we estimate negative coefficients for the variables of interest in five out of six specifications; however, none are near to being significantly different from zero at conventional confidence intervals. With these data, however, we observe many fewer weeks making our sample size much smaller. During these weeks, we observe only one-third as many entry events as we do with the VGChartz data. In addition, we lose degrees of freedom trying to model the growth in popularity in the Raptr network independently of the growth in popularity of video games. To do this, we include separate dummies for each week rather than week-of-year and year dummies. In light of this, it may not be surprising that the coefficients on competition are not statistically different from zero. Still, we consider the results from the VGChartz data as supportive of the hypothesis that publishers coordinate video game release dates.

\section{Conclusion}

While the video game industry is rapidly growing in importance, it is only beginning to be studied academically. It shares a number of features with other entertainment goods like movies, music, and books. There is a steady stream of new products. There are substantial upfront costs in production. Consumers have strong preferences for new releases and consumers have heterogeneous preferences for highly differentiated products. Within this context, one of the many strategic choices publishers must make is when to release a game.

We demonstrate the importance of product niches to understanding outcomes in this industry. We also suggest that the form of competition revolves around the characteristics embodied in the games rather than on the prices. This information indicates that the release date decision could have large profit implications depending on the level of competition in the 
publisher's product niche. Our results suggest that firms adjust their release dates so as to avoid periods of fiercest competition.

It is possible that consumers of entertainment goods will benefit from coordination on release dates. In contrast, consumers are almost certainly harmed by firms coordinating on price. Consumers could benefit from release coordination if it serves to smooth the flow of new product introductions within niches. Otherwise, heterogeneous consumers may experience peaks and valleys in the flow of their preferred niches of products. During valleys, they may have to resort to playing either inferior games from other niches or older games that have depreciated already. Release date coordination dampens the size of these peaks and valleys. Modeling this would require explicit accounting for the form of consumer heterogeneity and is suggested for possible future research. 


\section{References}

Bounie, D., Bourreau, M., Gensollen, M. and Waelbroeck, P. (2005). “Do Online Customer Reviews Matter? Evidence from the Video Game Industry.” Telecom ParisTech Working Paper ESS-08-02, Paris.

Calantone, R. J., Yeniyurt, S., Townsend, J. D. and Schmidt, J. B. (2010). “The Effects of Competition in Short Product Life-Cycle Markets: The Case of Motion Pictures.” Journal of Product Innovation Management 27(1): 349-361.

Chamberlain, E. (1962). “The Theory of monopolistic Competition: A re-orientation of the theory of value.” Harvard University Press, Vol. 38. Cambridge.

Chao, Y. and Derdenger, T. (2013). "Mixed Bundling in Two-Sided Markets in the Presence of Installed Base Effects," Management Science, 59(8), 1904-26.

Chevalier, J. and Mayzlin, D. (2006). “The effect of word of mouth on sales: Online book reviews.” Journal of Marketing Research 43: 345-354.

Claussen, J., Kretschmer, T. and Sprengler, T. (2010). “Backward Compatibility to Sustain Market Dominance: Evidence from the US Handheld Video Game Industry.” Discussion Papers in Business Administration 2010-05, Munich.

Clements, M. and Ohashi, H. (2005). “Indirect Network Effects and the Product Cycle: Video Games in the U.S., 1994-2002.” Journal of Industrial Economics 53 (4): 515-542.

Douglas, G. W. and Miller III, J. C. (1974). “Quality Competition, Industry Equilibrium, and Efficiency in the Price-Constrained Airline Market.” American Economic Review 64(4): 657-669. 
Dixit, A. K. and Stiglitz, J. (1977). "Monopolistic Competition and Optimal Product Diversity.” American Economic Review 67(3): 297-308.

Egenfeldt-Nielsen, S., Smith, J. H. and Tosca, S. P. (2008). “Understanding Video Games: The Essential Introduction.” Routledge.

Federal Trade Commission United States of America (2007). “Marketing Violent Entertainment Children”. A Report to the Congress. April.

Gandhi, A., Froeb, L., Tschantz, S. and Werden, G. J. (2008), "Post-Merger Product Repositioning." The Journal of Industrial Economics, 56(1): 49-67.

Gil, R. and Warzynski, F. (2010). "Vertical Integration, Exclusivity and Game Sales Performance in the US Video Game Industry”. Working Paper.

Grohsjean, T. and Kretschmer, T. (2008). "Product Line Extension in Hypercompetitive Environments: Evidence from the US Video Game Industry.” Discussion Papers in Business Administration 2008, Munich.

Henard, D. H. and Szymanski, D. M. (2001). "Why Some New Products Are More Successful Than Others.” Journal of Marketing Research 38(3): 362-375.

Joskow, P. L. (1980). “The Effects of Competition and Regulation on Hospital Bed Supply and the Reservation Quality of the Hospital.” Bell Journal of Economics 11(2): 421-447.

Kalyanaram, G. and Urban, G. L (1992). “Dynamic Effects of the Order of Entry on Market Share, Trial Penetration, and Repeat Purchases for Frequently Purchased Consumer Goods.” Marketing Science 11(Summer): 235-250.

Klepper, S. and Edward E. Leamer (1984), “Consistent Sets of Estimates for Regressions with Errors in All Variables,” Econometrica (52)1, 163-184 
Krider, R. E. and Weinberg, C. B. (1998). “Competitive Dynamics and the Introduction of New Products: The Motion Picture Timing Game.” Journal of Marketing Research 35: 1-15.

Montoya-Weiss, M. M. and Calantone, R. J. (1994). “Determinants of New Product Performance: A Review and Meta-Analysis.” Journal of Product Innovation Management 11(5): 397.

Moorthy, K. S. and PNG, I. P. L. (1992). "Market Segmentation, Cannibalization and the Timing of Product Introduction.” Management Science 38(3): 345-359.

Mussa, M. and Rosen, S. (1978). “Monopoly and Product Quality.” Journal of Economic Theory 18(2): 301-317.

Nault, B. R and Vandenbosch, M. B. (1996). "Eating Your Own Lunch: Protection Through Preemption.” Organization Science 7(3): 342-358.

Orbach, B. and Einav L. (2007). "Uniform prices for differentiated goods: The case of the movie-theater industry." International Review of Law and Economics 27(2), 129-153.

Palsson, C., Price, J. and Shores, J. (2013). “Ratings and Revenues: Evidence from Movie Ratings.” Contemporary Economic Policy 31(1): 13-21.

Plott, C. R. (1965). “Occupational Self-Regulation: A Case Study of the Oklahoma Dry Cleaners.” Journal of Law and Economics 8:195-222.

Richards, T. J. and Hamilton, S. F. (2006). "Rivalry in Price and Variety among Supermarket Retailers.” American Journal of Agricultural Economics 88(3): 710-726.

Rodríguez-Pinto, J., Carbonell, P. and Rodríguez-Escudero, A. I. (2011). “Speed or quality? How the order of market entry influences the relationship between market orientation 
and new product performance.” International Journal of Research in Marketing 28(1): 145-154.

Spence, A. M. (1976). “Product Selection, Fixed Costs and Monopolistic Competition.” Review of Economic Studies 43(2): 217-235.

Urban, G. L., Johnson, P. L. and Hauser, J. R. (1984). “Testing Competitive Market Structures.” Marketing Science 3(2): 83-112.

Vakratsas, D., Rao, R. C. and Kalyanaram, G. (2003). “An Empirical Analysis of Follower Entry Timing Decisions.” Marketing Letters 14(3): 203-216.

Zhu, F. and Zhang, X. (2010). “Impact of Online Consumer Reviews on Sales: The Moderating Role of Product and Consumer Characteristics.” Journal of Marketing 74: 133-148. 
Figure 1

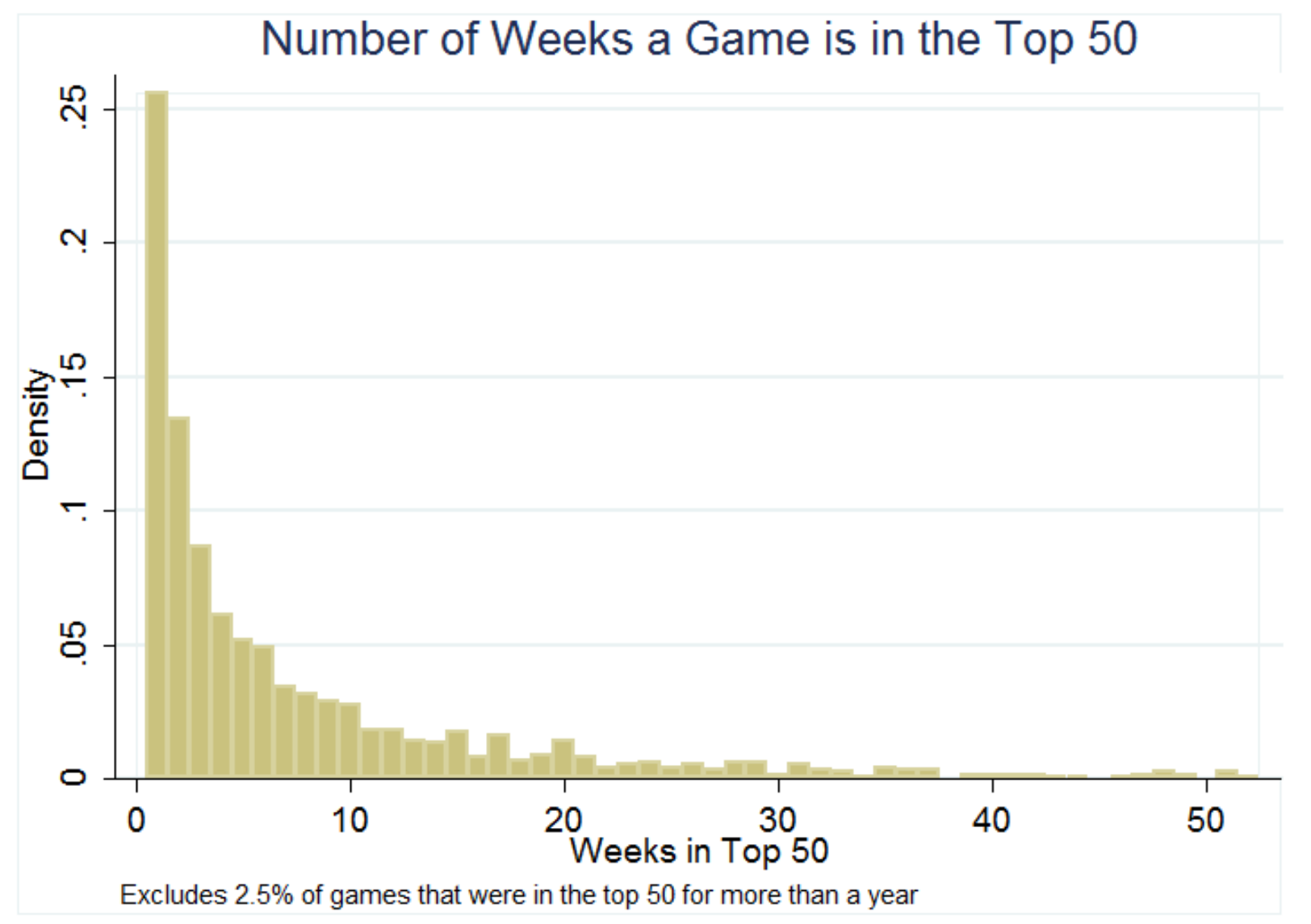


Figure 2

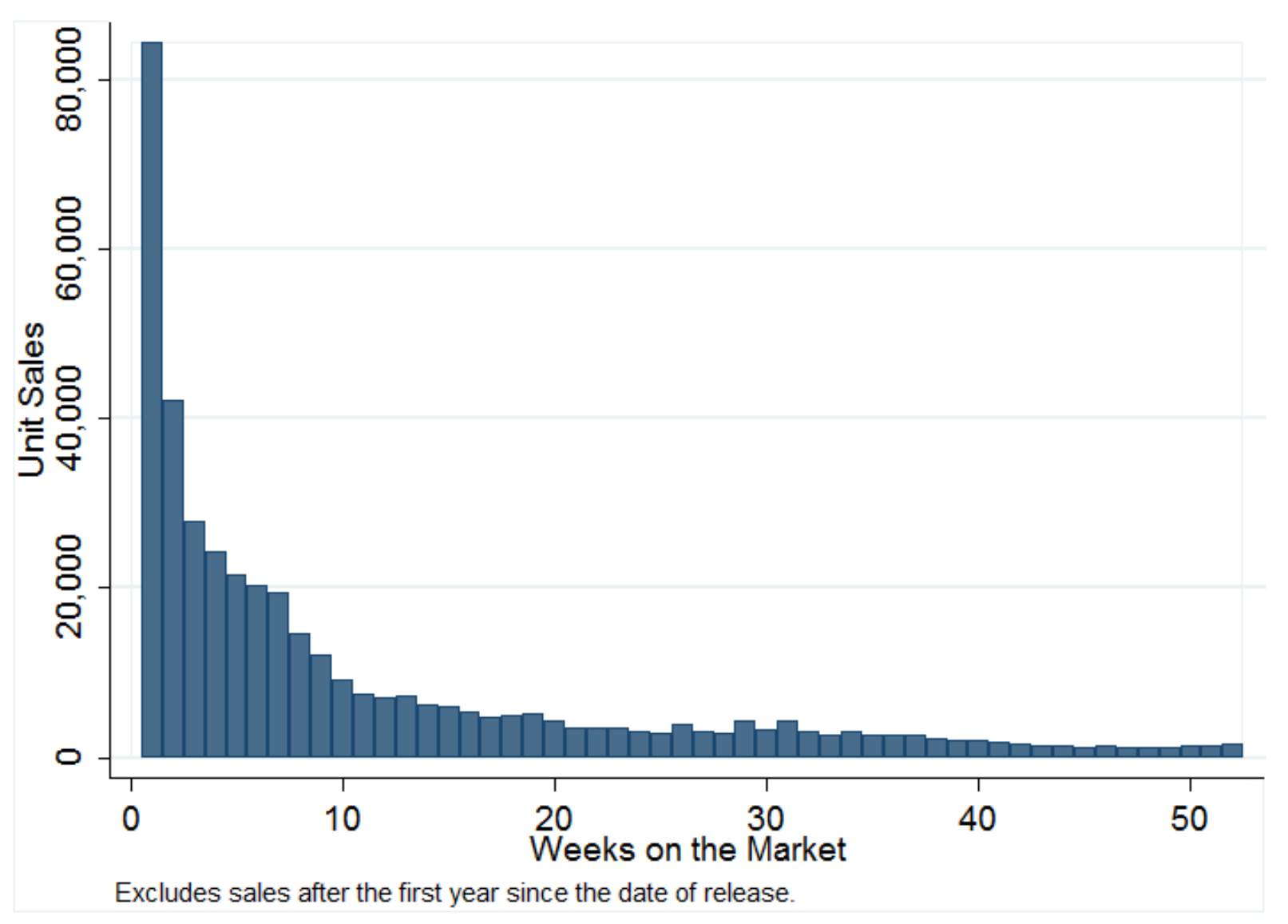


Figure 3

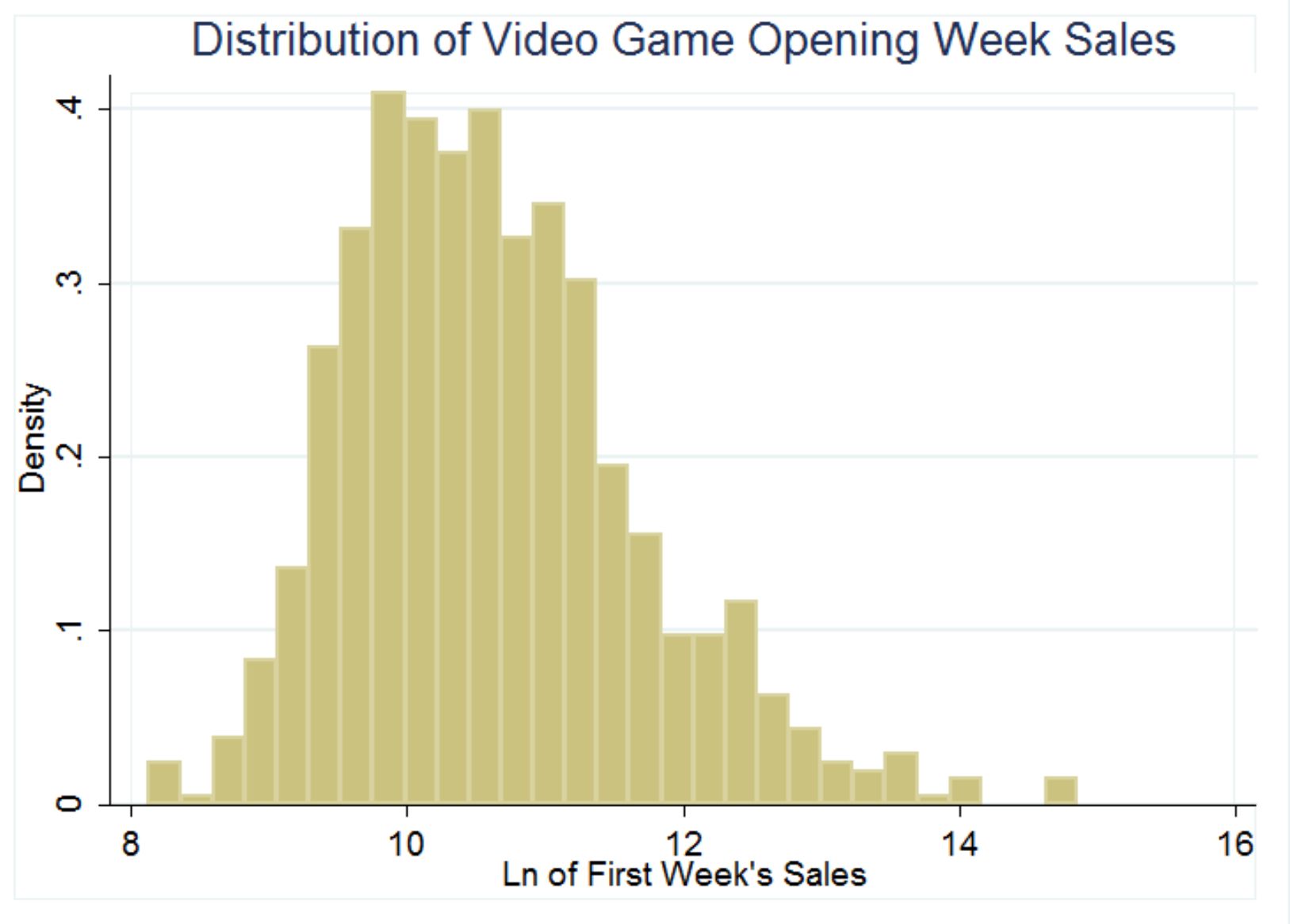


Table 1. Summary Statistics for VGChatz Consumer Substitution Sample

\begin{tabular}{lrr}
\hline Variable & Mean & Std. Dev. \\
\hline Sales & 38,523 & 76,825 \\
ln(Sales) & 10.00 & 0.95 \\
Game Age in weeks (E or E+) & 13.64 & 22.51 \\
Game Age in weeks (T or M) & 7.63 & 15.35 \\
Gamespot Score (GSS) & 7.71 & 1.25 \\
Gamespot Score (GSS) for All Other Games & 7.75 & 0.22 \\
GSS for games with same Console & 7.33 & 0.87 \\
GSS for games with same Genre & 7.42 & 1.04 \\
GSS for games with same ESRB & 7.33 & 0.94 \\
GSS for games with same Cohort & 10.53 & 6.79 \\
GSS for games with same Publisher & 2.71 & 3.98 \\
\hline Based on the 9,026 game by week observations for the 1,024 games \\
over 227 weeks included in the demand estimation. \\
\hline
\end{tabular}


Table 2. Summary Statistics for Raptr Consumer Substitution Sample

\begin{tabular}{lrr}
\hline Variable & \multicolumn{1}{c}{ Mean } & \multicolumn{1}{c}{ Std. Dev. } \\
\hline Adopters & 18.42 & 109.98 \\
Hours of Play & 18,400 & 111,995 \\
Ln(Aadopters) & 1.91 & 1.22 \\
Ln(Hours of Play) & 7.51 & 2.05 \\
Game Age in Days & 86.12 & 51.77 \\
Metacritic Score (Quality) & 74.93 & 12.39 \\
Quality all Other Games & 75.81 & 1.01 \\
Quality for Games with Same Console & 76.09 & 1.03 \\
Quality for Games with Same Genre & 76.65 & 2.09 \\
Quality for Games with Same ESRB Rating & 75.86 & 2.32 \\
Quality for Games with Same Cohort & 74.49 & 3.91 \\
Quality for Games with Same Publisher & 76.20 & 5.44 \\
\hline Based on the 33,713 game by day observations for the 361 games \\
over 94 weeks included in the demand estimation.
\end{tabular}


Table 3. Video Game Unit Sales Demand Estimates from VGChartz

\begin{tabular}{|c|c|c|c|}
\hline & \multicolumn{3}{|c|}{ Ln(Unit Sales) } \\
\hline $\begin{array}{l}\text { Gamespot Score } \\
\text { (Quality) }\end{array}$ & $\begin{array}{l}0.375 * * * \\
(0.097)\end{array}$ & $\begin{array}{l}0.420 * * * \\
(0.100)\end{array}$ & $\begin{array}{l}0.471^{* * *} \\
(0.106)\end{array}$ \\
\hline $\begin{array}{l}\text { Game Age in weeks } \\
\text { (E or } E+E S R B)\end{array}$ & $\begin{array}{l}-0.007 \\
(0.011)\end{array}$ & $\begin{array}{l}-0.006 \\
(0.011)\end{array}$ & $\begin{array}{l}-0.004 \\
(0.011)\end{array}$ \\
\hline $\begin{array}{l}\text { Game Age in weeks } \\
\text { ( } \mathrm{T} \text { or M ESRB) }\end{array}$ & $\begin{array}{l}-0.082^{* * *} \\
(0.021)\end{array}$ & $\begin{array}{l}-0.084^{* * * *} \\
(0.022)\end{array}$ & $\begin{array}{l}-0.084 * * * \\
(0.022)\end{array}$ \\
\hline $\begin{array}{l}\text { Quality for all other } \\
\text { games }\end{array}$ & & $\begin{array}{l}-1.720^{* * *} \\
(0.361)\end{array}$ & $\begin{array}{l}-0.448 \\
(0.350)\end{array}$ \\
\hline $\begin{array}{l}\text { Same Console } \\
\text { Quality }\end{array}$ & & & $\begin{array}{l}-0.096 * * \\
(0.041)\end{array}$ \\
\hline $\begin{array}{l}\text { Same Genre } \\
\text { Quality }\end{array}$ & & & $\begin{array}{l}-0.118 * \\
(0.069)\end{array}$ \\
\hline $\begin{array}{l}\text { Same ESRB } \\
\text { Quality }\end{array}$ & & & $\begin{array}{l}-0.123^{*} \\
(0.067)\end{array}$ \\
\hline $\begin{array}{l}\text { Same Cohort } \\
\text { Quality }\end{array}$ & & & $\begin{array}{l}-0.254 * * * \\
(0.090)\end{array}$ \\
\hline $\begin{array}{l}\text { Same Publisher } \\
\text { Quality }\end{array}$ & & & $\begin{array}{l}-0.005 \\
(0.069)\end{array}$ \\
\hline \multicolumn{4}{|l|}{ Dummies for: } \\
\hline Console & $\mathrm{X}$ & $X$ & $X$ \\
\hline Genre & $\mathrm{X}$ & $X$ & $X$ \\
\hline ESRB rating & $\mathrm{X}$ & $X$ & $X$ \\
\hline Cohort & $\mathrm{X}$ & $X$ & $X$ \\
\hline Publisher & $X$ & $X$ & $X$ \\
\hline Day-of-Week & $X$ & $X$ & $X$ \\
\hline Week & $X$ & $X$ & $X$ \\
\hline Observations & 9,296 & 9,296 & 9,271 \\
\hline \multicolumn{4}{|c|}{$\begin{array}{l}\text { Estimates from ML where distribution of errors is } \\
\text { truncated at the sales of that week's minimum sales. } \\
\text { Robust standard errors in parentheses. }{ }^{* * *} \mathrm{p}<0.01 \text {, ** } \\
\mathrm{p}<0.05,{ }^{*} \mathrm{p}<0.1\end{array}$} \\
\hline
\end{tabular}


Table 4. Video Game Demand Estimates from Raptr

\begin{tabular}{|c|c|c|c|c|c|c|}
\hline & \multicolumn{3}{|c|}{ Ln(Number of Adopters) } & \multicolumn{3}{|c|}{ Ln(Duration of Play) } \\
\hline Metacritic & $0.034 * * *$ & $0.033 * * *$ & $0.033 * * *$ & $0.073 * * *$ & $0.071 * * *$ & $0.074 * * *$ \\
\hline Score & $(0.000)$ & $(0.000)$ & $(0.001)$ & $(0.001)$ & $(0.001)$ & $(0.001)$ \\
\hline $\begin{array}{l}\text { Game Age in } \\
\text { days }\end{array}$ & $\begin{array}{l}-0.017 * * * \\
(0.001)\end{array}$ & $\begin{array}{l}-0.017 * * * \\
(0.001)\end{array}$ & $\begin{array}{l}-0.018 * * * \\
(0.001)\end{array}$ & $\begin{array}{l}-0.017 * * * \\
(0.001)\end{array}$ & $\begin{array}{l}-0.017 * * * \\
(0.001)\end{array}$ & $\begin{array}{l}-0.018 * * * \\
(0.001)\end{array}$ \\
\hline $\begin{array}{l}\text { Quality for all } \\
\text { other Games }\end{array}$ & & $\begin{array}{l}-0.161^{* * *} \\
(0.032)\end{array}$ & $\begin{array}{l}0.150^{* * *} \\
(0.043)\end{array}$ & & $\begin{array}{l}-0.322^{* * * *} \\
(0.055)\end{array}$ & $\begin{array}{l}0.475^{* * *} \\
(0.077)\end{array}$ \\
\hline $\begin{array}{l}\text { Same Console } \\
\text { Quality }\end{array}$ & & & $\begin{array}{l}-0.430^{* * *} \\
(0.027)\end{array}$ & & & $\begin{array}{l}-0.929 * * * \\
(0.055)\end{array}$ \\
\hline $\begin{array}{l}\text { Same Genre } \\
\text { Quality }\end{array}$ & & & $\begin{array}{l}0.009 * * \\
(0.004)\end{array}$ & & & $\begin{array}{l}0.027 * * * \\
(0.006)\end{array}$ \\
\hline Same ESRB & & & -0.003 & & & $-0.051 * * *$ \\
\hline Quality & & & $(0.004)$ & & & $(0.007)$ \\
\hline Same Cohort & & & $-0.021 * * *$ & & & $-0.018 * * *$ \\
\hline Quality & & & $(0.001)$ & & & $(0.002)$ \\
\hline Same Publish. & & & $-0.021 * * *$ & & & $-0.014 * * *$ \\
\hline Quality & & & $(0.002)$ & & & $(0.003)$ \\
\hline \multicolumn{7}{|l|}{ Dummies for: } \\
\hline Console & $\mathrm{X}$ & $X$ & $X$ & $\mathrm{X}$ & $\mathrm{X}$ & $\mathrm{X}$ \\
\hline Genre & $\mathrm{X}$ & $\mathrm{X}$ & $\mathrm{X}$ & $\mathrm{X}$ & $X$ & $\mathrm{X}$ \\
\hline ESRB rating & $\mathrm{X}$ & $\mathrm{X}$ & $\mathrm{X}$ & $\mathrm{X}$ & $\mathrm{X}$ & $\mathrm{X}$ \\
\hline Cohort & $\mathrm{X}$ & $X$ & $X$ & $X$ & $X$ & $X$ \\
\hline Publisher & $\mathrm{X}$ & $\mathrm{X}$ & $X$ & $\mathrm{X}$ & $\mathrm{X}$ & $\mathrm{X}$ \\
\hline Week & $\mathrm{X}$ & $\mathrm{X}$ & $\mathrm{X}$ & $\mathrm{X}$ & $\mathrm{X}$ & $X$ \\
\hline Observations & 36,292 & 36,292 & 35,387 & 34,547 & 34,547 & 33,713 \\
\hline
\end{tabular}


Table 5. Poisson regression of number of entrants in a niche from VGChartz over $225 \mathrm{w}$ eeks

\begin{tabular}{|c|c|c|c|c|c|c|c|c|c|}
\hline & \multicolumn{3}{|c|}{ Console } & \multicolumn{3}{|c|}{ Genre } & \multicolumn{3}{|c|}{ ESRB } \\
\hline $\begin{array}{l}\text { Number of Entrants } \\
\text { Previous Week }\end{array}$ & $\begin{array}{l}-0.072 \\
(0.050)\end{array}$ & & & $\begin{array}{l}-0.072 * * * \\
(0.027)\end{array}$ & & & $\begin{array}{l}-0.055^{* *} \\
(0.022)\end{array}$ & & \\
\hline $\begin{array}{l}\text { Number of Titles } \\
\text { Previous Week }\end{array}$ & & $\begin{array}{l}-0.014 \\
(0.021)\end{array}$ & & & $\begin{array}{l}-0.058^{* *} \\
(0.015)\end{array}$ & & & $\begin{array}{l}-0.002 \\
(0.011)\end{array}$ & \\
\hline $\begin{array}{l}\text { Unit Sales } \\
\text { Previous Week }\end{array}$ & & & $\begin{array}{l}0.739 * * \\
0.321)\end{array}$ & & & $\begin{array}{l}0.344^{* *} \\
0.150)\end{array}$ & & & $\begin{array}{l}-0.568^{* * *} \\
(0.137)\end{array}$ \\
\hline Dummies for: & & & & & & & & & \\
\hline Week & $X$ & $\mathrm{X}$ & $\mathrm{X}$ & $\mathrm{X}$ & $\mathrm{X}$ & $\mathrm{X}$ & $\mathrm{X}$ & $\mathrm{X}$ & $X$ \\
\hline Year & $\mathrm{X}$ & $\mathrm{X}$ & $\mathrm{X}$ & $\mathrm{X}$ & $\mathrm{X}$ & $\mathrm{X}$ & $\mathrm{X}$ & $\mathrm{X}$ & $\mathrm{X}$ \\
\hline Niche & $\mathrm{X}$ & $\mathrm{X}$ & $\mathrm{X}$ & $\mathrm{X}$ & $\mathrm{X}$ & $\mathrm{X}$ & $\mathrm{X}$ & $\mathrm{X}$ & $\mathrm{X}$ \\
\hline Niche×Year & $\mathrm{X}$ & $\mathrm{X}$ & $\mathrm{X}$ & $\mathrm{X}$ & $\mathrm{X}$ & $\mathrm{X}$ & $\mathrm{X}$ & $\mathrm{X}$ & $\mathrm{X}$ \\
\hline Observations & 1,350 & 1,350 & 1,350 & 1,800 & 1,800 & 1,800 & 900 & 900 & 900 \\
\hline
\end{tabular}

Standard errors in parentheses. ${ }^{* * *} \mathrm{p}<0.01,{ }^{* *} \mathrm{p}<0.05,{ }^{*} \mathrm{p}<0.1$ 
Table 6. Poisson regression of number of entrants in a niche from RAPTR over 94 weeks

\begin{tabular}{|c|c|c|c|c|c|c|}
\hline & \multicolumn{2}{|c|}{ Console } & \multicolumn{2}{|c|}{ Genre } & \multicolumn{2}{|c|}{ ESRB } \\
\hline $\begin{array}{l}\text { Number of Entrants } \\
\text { Previous Weeks }\end{array}$ & $\begin{array}{l}-0.004 \\
(0.069)\end{array}$ & & $\begin{array}{l}-0.010 \\
(0.070)\end{array}$ & & $\begin{array}{l}-0.123 \\
(0.099)\end{array}$ & \\
\hline $\begin{array}{l}\text { Number of Game Adopters } \\
\text { Previous Week }\end{array}$ & & $\begin{array}{l}0.263 \\
(1.364)\end{array}$ & & $\begin{array}{l}-0.127 \\
(0.943)\end{array}$ & & $\begin{array}{l}-0.210 \\
(1.094)\end{array}$ \\
\hline \multicolumn{7}{|l|}{ Dummies for: } \\
\hline Week & $\mathrm{X}$ & $\mathrm{X}$ & $\mathrm{X}$ & $\mathrm{X}$ & $\mathrm{X}$ & $\mathrm{X}$ \\
\hline Niche & $\mathrm{X}$ & $\mathrm{X}$ & $\mathrm{X}$ & $\mathrm{X}$ & $\mathrm{X}$ & $\mathrm{X}$ \\
\hline Observations & 376 & 376 & 564 & 564 & 470 & 470 \\
\hline
\end{tabular}

Standard errors in parentheses. ${ }^{* * *} \mathrm{p}<0.01,{ }^{* *} \mathrm{p}<0.05, * \mathrm{p}<0.1$ 